University of Nebraska - Lincoln

DigitalCommons@University of Nebraska - Lincoln

Faculty Publications, UNL Libraries

Libraries at University of Nebraska-Lincoln

1991

Creativity and Innovation in an Organized Anarchy

Joan Giesecke

Universityof Nebraska-Lincoln, jgiesecke1@unl.edu

Follow this and additional works at: https://digitalcommons.unl.edu/libraryscience

Part of the Library and Information Science Commons

Giesecke, Joan, "Creativity and Innovation in an Organized Anarchy" (1991). Faculty Publications, UNL Libraries. 254.

https://digitalcommons.unl.edu/libraryscience/254

This Article is brought to you for free and open access by the Libraries at University of Nebraska-Lincoln at DigitalCommons@University of Nebraska - Lincoln. It has been accepted for inclusion in Faculty Publications, UNL Libraries by an authorized administrator of DigitalCommons@University of Nebraska - Lincoln. 


\title{
Creativity and Innovation in an Organized Anarchy
}

\author{
Joan R. Giesecke
}

\begin{abstract}
SUMMARY. Organizations can respond to change in their environments in a variety of planned and unplanned ways. In complex organizations, when the environment is unstable, managers need to examine their assumptions about how organizations function in order to develop effective strategies for introducing creativity and change. This essay reviews the assumptions behind theories of organizational decision making, explores how those assumptions affect how managers decide strategies for introducing change, and offers some ideas on how to introduce creativity into organizations that face ambiguous internal and external environments.
\end{abstract}

\section{INTRODUCTION}

Organizations can create their own futures and respond to changes in their environment in a variety of ways with planned and unplanned strategies. When the environment is relatively stable and predictable, organizations turn to planned change as a way for the organization to stay in tune with its environment. Planned changes emphasize rational, logical thought and decision making techniques. These processes focus on performance and management within the existing system. Planned change involves events that can be anticipated. It is a response to what is viewed as a closed system.

However, when organizations face an unstable environment and when their internal processes are also changing, a different approach to change may be needed. In this setting managers need to examine their assumptions about how organizations function in or-

Joan Giesecke is Associate Dean of Libraries at the University of Nebraska, Lincoln, NB.

(C) 1991 by The Haworth Press, Inc. All rights reserved. 
der to develop effective strategies for introducing creativity and change into their organizations. This article will review the assumptions behind theories of organizational decision-making, will explore how those assumptions affect how managers decide strategies for introducing change, and will offer some ideas on how to introduce creativity into organizations that face ambiguous internal and external environments.

\section{BACKGROUND}

Classical theories of organizations emphasize rational thought and controlled, predictable actions. The rational model assumes that organizations have understandable, consistent goals which are used to guide organizational actions. In this model decision making consists of the following steps: the manager identifies a problem; identifies various alternatives for solving the problem; evaluates the alternatives based on organizational preferences or goals; and chooses an alternative that maximizes benefits for the organization. Recent empirical studies of organizational decision-making, however, portray a different, more confusing picture of organizations. Studies of managers' work in organizations found that the manager's job is inherently open-ended where planning is done haphazardly, work is fragmented, and interruptions are common. ${ }^{1}$ Problems arrive in no particular order and are handled sequentially. Managers rarely consider rational objectives and planned strategies when deciding which problems to solve. Rather managers are likely to choose those problems which fit with the manager's own view of his/her role in the organization.

As theorists coped with the discrepancies between the classical model and the real world, the rational model as the ideal gave way to models of incrementalism and satisficing. ${ }^{2}$ Incrementalists argue that most decisions consist of making small adjustments to the status quo. These incremental changes emerge from a bargaining process among decision makers where the best alternative is the one on which decision makers can agree, rather than being the alternative that necessarily maximizes benefits. Abstract goals and objectives are not debated. Instead decision makers focus on current programs and policies where adjustments can be made. 
An alternative to the incremental model is found in the work of Herbert Simon and his approach known as satisficing. This model recognizes that decision makers have limited access to information and limited ability to process information. In this approach decision makers stop searching for alternatives as soon as an alternative is found which meets the manager's minimum acceptable goals. That is, the manager chooses the alternative that is sufficient or "good enough."

Still, these models could not account for all of the events that make up organizational decision-making. Recent studies of organizations have, in fact, questioned whether or not organizational goals can be known. These studies find that decision makers may not have well defined preferences. Alternative courses of action may not be well understood. The set of possible outcomes or solutions may not be well explicated. ${ }^{3}$

Furthermore, studies showed that participants appear and disappear in the organization, varying the amount of time they are willing to spend on any given issue. Problems seem to float in organizations and solutions may precede problem identification. Goals might be discovered after action had occurred. In other words, the simplified models of organizational choice did not explain much of what is observed in organizational settings.

These discrepancies, between observed behavior and theoretical models that are based on the assumption that goals guide actions, led James G. March, Michael Cohen and Johan Olsen to develop a different approach to use in describing organizational behavior in complex organizations. ${ }^{4}$ They address the messiness of managerial decision making where identification of problems, discovery of alternatives, evaluation of solutions, and making of choices can occur together, vaguely, or not at all. They propose a model that characterizes organizations as organized anarchies. In this view they mean any organization that exhibits the following characteristics:

a. Problematic Goals. The organization appears to operate on a variety of inconsistent and ill-defined preferences.

b. Unclear Technology. The organizational members do not always understand organizational processes. The organization seems to run on a trial-and-error basis. 
c. Fluid Participation. Participants in the organization vary among themselves in the amount of time and effort they devote to the organization. ${ }^{5}$

In such organizations as described above, ambiguity dominates and participants have varying ideas about what is happening or why it is happening. Individuals do not necessarily agree about organizational goals. They find themselves in a more complex and less stable world than is described in most standard theories of organizational behavior.

According to March and Olsen, in organizations that exhibit these characteristics, decision-making processes are messy and complex. They argue that problems, solutions, participants, and decision-making opportunities are separate entities that can exist independently within an organization. Problems, solutions, and participants can be viewed as streams that flow through an organization and may or may not come together in a decision-making opportunity. The decision-making opportunity is viewed as a garbage can where problems, solutions, and participants meet in no particular order. At that point the organization may choose to make a decision, to ignore all of the problems and solutions raised in the decision-making opportunity, or may choose to resolve other problems in the organization which were not part of the original decisionmaking opportunity or garbage can.

In this garbage can environment, there are no obvious rules for linking problems and solutions together to ensure that problems are resolved. It is difficult to examine organizational goals, objectives, rules and regulations, and predict which participants are likely to be present at any given meeting or decision-making opportunity or which problems or solutions may be raised. Decisions, then, will not be made through the traditional steps of identifying issues, examining alternatives, and proposing solutions. Rather, solutions may precede problems, and individual problems, solutions, or participants may appear in any number of decision-making opportunities.

The outcome of the decision-making process may not necessarily reflect the intentions of the participants. Outcomes are most likely to be the result of fortuitous timing rather than representing the 
explicit choice of the participants. The decision-making process in this model is a dynamic process, where problems, solution, and participants move throughout the organization and where events are not dominated by intention. Particularly in times of change, when an organization may face many problems at the same time, the intentions of participants are likely to be lost in the flow of problems, solutions, and people.

\section{ACADEMIC LIBRARIES AS ORGANIZED ANARCHIES}

Universities are prototypical organized anarchies, or organizations that fit the characteristics of March and Olsen's model. Institutional goals are vague, conflicting and rarely understood. Organizational processes are familiar, but not understood. The major participants in the organization, the faculty and students, wander in and out of the process, participating in organizational activities and decision-making opportunities only until they find something better to do with their time. The organizations do not function solely as hierarchies. Rather, the setting includes collegial elements of faculty governance, and individual faculty entrepreneurial behavior, blended with an administrative hierarchy.

Within the framework of the university, the academic library as a service unit also reflects the characteristics of an organized anarchy. Academic libraries have multiple goals which may be in conflict as the library serves its various patrons. Provision of service to undergraduates must compete with specialized resources needed to support faculty research. The desire to preserve a collection may be in conflict with the need to provide users with access to information. Each market the library serves may need different types of resources and different services. Furthermore professional standards may dominate organizational preferences rather than the goals of the organization guiding its activities.

Academic libraries also have unclear organizational technologies. That is, processes are not clearly understood by the library faculty and staff. There is little overall agreement in the field as to what services a library should provide or how these services relate to the outputs of the educational process. 
c. Fluid Participation. Participants in the organization vary among themselves in the amount of time and effort they devote to the organization. ${ }^{5}$

In such organizations as described above, ambiguity dominates and participants have varying ideas about what is happening or why it is happening. Individuals do not necessarily agree about organizational goals. They find themselves in a more complex and less stable world than is described in most standard theories of organizational behavior.

According to March and Olsen, in organizations that exhibit these characteristics, decision-making processes are messy and complex. They argue that problems, solutions, participants, and decision-making opportunities are separate entities that can exist independently within an organization. Problems, solutions, and participants can be viewed as streams that flow through an organization and may or may not come together in a decision-making opportunity. The decision-making opportunity is viewed as a garbage can where problems, solutions, and participants meet in no particular order. At that point the organization may choose to make a decision, to ignore all of the problems and solutions raised in the decision-making opportunity, or may choose to resolve other problems in the organization which were not part of the original decisionmaking opportunity or garbage can.

In this garbage can environment, there are no obvious rules for linking problems and solutions together to ensure that problems are resolved. It is difficult to examine organizational goals, objectives, rules and regulations, and predict which participants are likely to be present at any given meeting or decision-making opportunity or which problems or solutions may be raised. Decisions, then, will not be made through the traditional steps of identifying issues, examining alternatives, and proposing solutions. Rather, solutions may precede problems, and individual problems, solutions, or participants may appear in any number of decision-making opportunities.

The outcome of the decision-making process may not necessarily reflect the intentions of the participants. Outcomes are most likely to be the result of fortuitous timing rather than representing the 
that can appear in the organization. Managers need to create an organizational environment that promotes rational decision-making and rational organizational structures. The development of an agreed to set of organizational values and beliefs can be used to hold the organization together so that decision-making processes do not deteriorate into the randomness of the garbage can model. Planned change strategies such as strategic planning exercises can be used to set a direction for the organization while increasing the rules and regulations that guide decision-making processes.

\section{Adapt to the Process}

This second strategy is a matter of adopting a managerial style that works with the confusion found in the decision-making process. Tactics such as setting deadlines, spending a lot of time on a problem, persisting with an issue, and managing unobtrusively can be effective in decreasing the random movement of problems, solutions, and participants and increasing the ability of a manager to influence the process. Participants can also introduce a large number of items or projects into the system in order to distract other participants so that they do not spend too much time on any given topic. In each case, these tactics center on an individual taking the initiative and adapting to the anarchial environment. Although these tactics are available to any one who wants to use them, generally people have more interesting things to do than to try to manage decision-making processes. ${ }^{\text {? }}$

Another version of adapting to an organized anarchy process provided by March and Cohen begins with the idea that managers need to think about organizations in complex ways that are not dependent upon pre-existing goals. They suggest that managers: "think of goals as hypotheses, subject to experimentation and doubt; treat intuition as real; consider inconsistencies between expressed values and behavior as transitory rather than as fact." Their argument is that by recognizing and accepting the ambiguity of an organized anarchy managers can begin to discover new ways to cope with the process. ${ }^{8}$ 


\section{Embrace the Process}

This third set of strategies has as its goal helping managers to increase flexibility in the organization by embracing the processes found in an organized anarchy. This third set is particularly interested in encouraging creativity and innovation and in developing open processes that maximize the ability of participants to generate new ideas. These strategies are appropriate when an organization is facing a changing environment and changing values.

First, to increase flexibility in the organization, managers may choose to consciously suspend rules and regulations and to suspend rational imperatives toward consistency in order to promote less rational, planned behavior in the exploration of new ideas. This tactic, where action precedes thought so that people act first and think later, is described by March and his colleagues as a way to increase play in the organization.

Play allows for experimentation in the organization. It relieves participants from the need to appear rational and allows for actions that may seem unintelligent or irrational in order to explore alternative ideas and concepts. Play allows participants to combine skills in novel sets to increase flexibility in the organization. For example, unstructured brainstorming sessions are one way to begin to allow for play in the organization. "What play does is unhook behavior from the demands of real goals. The person gets experience in combining pieces of behavior that would not be juxtaposed in a utilitarian world." Of course, play is only a temporary suspension of rules. At some point the ideas and activities of participants will need to be incorporated into the formal organizational structure.

One caveat, however, in using tactics to promote playfulness in the organization is that the participants need to be willing to openly debate problems in the organization and to seek new approaches to examining issues. Without this willingness by participants the process of promoting play will be difficult at best. Participants must trust and believe that managers will seriously consider the ideas and suggestions that result from a non-rational process. Without that trust, participants are likely to view the process with some suspicion because the process is not an accepted part of more traditional approaches to organizational decision-making and behavior. To suc- 
ceed in the organization, then, playfulness needs to be accepted and supported by all parties involved in the process and cannot easily be imposed by one group on another. ${ }^{10}$

A second set of strategies for encouraging creativity in organized anarchies involve taking advantage of unanticipated changes or crises in the environment as opportunities to review how the organization is responding to a changing environment. Here managers need to seek unstructured ways to gather information about the organization in order to learn what is really going on in the organization. They also need to look for ways to encourage the development of spontaneous processes that can cope with unanticipated changes in the environment. Such tactics as Management by Walking Around provide an avenue for managers to use in order to tap into the informal organizational structure. "Managers can use the informal organizational structure to gather information, to assess the environment, and to unobtrusively influence organizational processes.

Organizational designs can also be used to encourage the development of creative structures. Organic structures, in contrast to mechanistic, machine-age structures, allow for adaptation to unplanned change. Such designs as the use of task forces, small working groups, and temporary working groups, are all flexible structures that encourage adaptation to change. These groups can respond to a crisis, experiment with various projects, identify problems, propose solutions more quickly than traditional bureaucratic structures. The use of these types of groups can encourage entrepreneurship in the organization and can foster creativity while avoiding the need to impose rational, bureaucratic constraints on the process. The tactics can help participants move beyond cognitive limits of rationality to a different plane of hunches, dreams, and speculation to allow the organization to respond to the unknown in its environment.

Of course, with all of these options, coordination of actions is essential if the work of the groups is to benefit the organization. The groups will fail if management loses interest in them, does not take their work seriously, and ignores the work of the groups.

Taking a slightly different approach and looking at how people think about organizations, Karl Weick argues for processes that encourage participants to see organizations in novel ways. By learning 
to think of organizations as organized anarchies, garbage cans, and such, managers can move beyond the cognitive limits of the rational model to exploring different ways for bringing about change. If an organization is narrow in its vision or image of itself, it won't be able to make interesting changes in light of changes in its surroundings. "An organization that sees itself in novel images, images that are permeated with diverse skills and sensitivities, thereby is equipped to deal with altered surroundings when they appear."

Weick goes on to suggest additional strategies managers can use to be effective in complex organizations. He suggests that managers not panic in the face of disorder because disorder may signal an effective process for coping with ambiguity. Too, Weick warns against overmanaging the organization. Not all things happen at once, so managers can intervene judiciously and still affect overall changes. Events take time and managers do not need to be involved in all phases of an operation for the project to proceed smoothly. Third, Weick argues that any action by the organization, even chaotic action, is better than inaction. This is because actions help clarify what an organization is doing. It provides tangible results for participants to analyze and understand. Next Weick notes that there are no simple solutions or answers. Problems evolve and rarely have a distinct beginning and ending. Interdependent systems result in open-ended issues. By addressing issues on a small scale, fine tuning the organization, and always looking for changes in the organization surroundings, managers are in a better position to adjust to changes and to keep the organization moving forward. Finally Weick argues that managers need to complicate their views of the organization to begin to recognize the ambiguous processes that hold the organization together. Most organizational models try to simplify the organization to a few key variables in an attempt to meaningfully explain organizational behavior. In contrast to this approach, Weick argues that, in complex organizations, this simplification process can lead to simple but inadequate answers to complex issues. By recognizing the messy, diverse confusion that typifies today's organizations, and realizing that organizations are processes rather than static entities, managers will be better able to develop and implement creative solutions to organizational problems. To bring creativity and innovation into the organization, man- 
agers need to "begin to take pleasure in the process rather than pleasure in the outcome." 13

\section{UTILITY OF THE MODELS}

But in a practical sense, where does all this advice lead the manager of complex organizations? Should we abandon the prescriptions of the rational, traditional models for the nonrational, more fluid advice for managing organized anarchies? As our organizations become more complex and our environment continues to change in unanticipated ways, it becomes more evident that no one model will answer all of our concerns. Basically to succeed in complex organizations, we need to balance planned and unplanned strategies by using both rational and nonrational approaches to organizational decision making. We need a combination of reforming and adapting strategies along with strategies that embrace the messy processes that make up organized anarchies. To accomplish this, theorists such as Bo Hedberg, Paul Nystrom and William Starbuck advocate that we stop thinking of organizations as solid objects, and begin thinking of them as mobile tents. ${ }^{14}$ The image of an organization as a tent emphasizes flexibility, creativity, immediacy, and initiative rather than authority, clarity, and decisiveness. Tents can easily move as the environment or foundation for the organization shifts. They can take advantage of those changes without destroying the fundamental structure of the organization. Realistically, few organizations are as flexible as tents. Nonetheless, in spite of the fact that most management theories emphasize rational thought and planned approaches to change, we do need to think in terms of adaptive, flexible structures that can stay balanced while coping with change. Balance is needed between a siege mentality where organizational actors seek to protect the structure, centralize authority, and solve short run crises with radical change that destroys the organization.

In our complex environment, balance is needed in six areas for the organization to succeed and survive. First, we need minimal consensus, or a balance between complete consensus and the dangers of group think, and open warfare or dissension. Between these extremes lies a middle ground of cooperation rather than complete 
cooptation. Second, we need minimal contentment, and a balance between complacency and discontentment. Organizational participants need to feel a part of the organization but not so comfortable that they are unmotivated to deal with change. Third, we need minimal affluence and a balance between excess resources that can lead to waste and such scarce resources that we can not function. Minimal faith in goals is also important. We need to balance our planning activities with the knowledge that we can not accurately predict the future. We want to plan for the future but not rely so on our plans that we lose sight of reality. Fifth, the organization needs minimal consistency and a balance between such slow evolution that nothing happens and a wide revolution that destroys the organization. Finally, we need minimal rationality and a balance between objectivity and ambiguity. A creative organization coping with change and creating its own future needs ambiguous authority structures, inconsistent statuses, overlapping responsibilities, competitive activities, volatile rules, and varying criteria for decision making. This less than efficient organization may not save resources, but the added flexibility and innovation will keep the organization afloat in a changing world.

\section{CONCLUSION}

In summary, a dynamic balance is needed between planning and overlapping, unplanned, nonrational processes to keep the organization current. Planned change strategies such as strategic planning help an organization decrease the anarchy in its processes and allow the organization to respond to identified changes in the environment. These processes encourage stability by considering known elements in the environment and incorporating them into the planning process. When they are done well they allow the organization to set its course in a changing environment. Badly done, however, they can lead to an organization drifting in the backwater of its environment, unable to respond creatively to change.

Unplanned change strategies that embrace the anarchy in the organization, allow the organization to move beyond the cognitive limits of rationality to a different level of hunches and dreams so that organizations can respond to the unknown in their environ- 
ments and to create their own destinies. Successfully done these strategies can lead to innovative, creative organizations. Badly done they may lead to chaos.

\section{NOTES}

1. Henry Mintzberg, The Nature of Managerial Work (New York: Harper \& Row, 1973).

2. See Charles Lindblom, "The Science of Muddling 'Through,", Public Administration Review 19 (1957): 79-88 and Herbert Simm, Administration Behavior (New York: Free Press, 1976).

3. David Cooper and David Hayes, "Accounting in Organized Anarchies: Understanding and Designing Accounting Systems in Ambiguous Situations," Accounting, Organization, and Society 6 (1981): 176.

4. James G. March and Johan Olsen, Ambiguity and Choice in Organization (Bergen: Universitetstorlaget, 1979).

5. James G. March and Michael Cohen, Leadership and Ambiguity (Boston: Harvard Business School Press, 1986), p. 3.

6. James G. March and Roger Weissinger-Baylor, Ambiguity and Command (Massachusetts: Pitman Publishing, Inc., 1986), pp. 25-28.

7. James G. March and Michael Cohen, p. 215.

8. James G. March and Michael Cohen, p. 222.

9. Karl Weick, Social Psychology of Organizing (New York: Random House, 1979), p. 248.

10. Richad West, "Will Playfulness be Possible in University Management," College Board Review 112 (1979): 14-19.

11. Thomas J. Peters and Robert H. Waterman, Jr., In Search of Excellence (New York: Warner Books, (1982), p. 122.

12. Karl Weick, p. 249.

13. Karl Weick, p. 263.

14. Bo Hedberg, Paul Nystrom, and William Starbuck, "Camping on Seesaws: Prescriptions for a Self-Designing Organization," Adminstrative Science Quarterly 21 (1976): 41-65. 